\title{
PROUST, RUSKIN E WHISTLER: TRADUÇÃO, POLÊMICA E TRAIÇÃo
}

Luciana Persice Nogueira ${ }^{1}$

RESUMO: As duas traduções realizadas por Marcel Proust antes do início da redação de $A$ la recherche $d u$ temps perdu têm posição e função estratégica na afirmação do escritor enquanto ensaísta, crítico e teórico. Seus comentários aos títulos do esteta e pensador John Ruskin levam-no a rivalizar com o autor traduzido, a polemizar com seus pares quanto ao entendimento da obra e a marcar sua originalidade dentro do quadro artístico e intelectual da época. Levam-no, portanto, à inelutável "traição" tradutória, que se expressa, inclusive, através do elogio ao maior antagonista de Ruskin, o pintor norte-americano James Whistler, e do papel simbólico que lhe confere em sua obra.

PALAVRAS-CHAVE: tradução, estética, literatura, crítica literária.

RÉSUMÉ : Les deux traductions realisées par Marcel Proust avant le début de la rédaction de $A$ la recherche $d u$ temps perdu ont une position et une fonction estratégiques dans l'affirmation de l'écrivain en tant qu'essaiste, critique et théoricien. Ses commentaires aux titres de l'esthète et penseur John Ruskin le mènent a rivaliser avec l'auteur traduit, a polémiquer avec ses pairs par rapport à l'entendement de l'oeuvre, et a marquer son originalité dans le contexte artistique et intellectuel de l'époque. Ils le mènent donc a l'ineluctable "trahison" traductrice, qui s'exprime, aussi, par l'éloge du plus grand antagoniste de Ruskin, le peintre nord-americain James Whistler, et par le rôle symbolique qu'il lui confère dans son oeuvre.

MOTS-CLÉS : traduction, esthétique, litterature, critique littéraire.

\footnotetext{
${ }^{1}$ A autora possui mestrado, doutorado e pós-doutorado em Letras Neolatinas pela UFRJ. Leciona no IPEL/PUC-RJ. E-mail: luciana.persice@yahoo.com.br
} 


\section{A tradução}

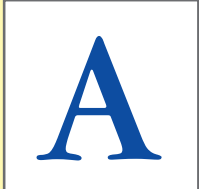

crítica literária francesa é praticamente unânime ao eleger Marcel Proust (1871-1922) como um "clássico" da literatura nacional, mas vê-se em certo embaraço quando se propõe a dar conta da "era das traduções" proustiana. Entre os dois títulos de ficção publicados por Proust em vida, Les Plaisirs et les Jours (1896) e $A$ la Recherche $d u$ Temps Perdu (1913-1927 - que só será totalmente publicada postumamente), Proust se dedicou à tradução de dois livros do pensador e esteta britânico John Ruskin (1819-1900): La Bible d'Amiens (1904) e Sésame et leslys (1906).

A posição oficial da editora Gallimard (principal editora da obra de Proust) não deixa margem a dúvidas: a era das traduções foi um erro. Bernard de Fallois, em seu prefácio a Contre Sainte-Beuve, considera que "Ruskin marcava... uma regressão [“un repli”], um trabalho de erudição que o desviava de sua atividade profunda" (PROUST, 1994, p. 16). Muitos anos depois, mas na mesma linha, Jean-Yves Tadié, na sua introdução à edição da Pléiade de $A$ la Recheche du Temps Perdu, afirma que Proust fez "tábua rasa do passado e de Ruskin, a quem disse adeus" ao começar a redação da Recherche (TADIÉ, 1987, p. xxiv).

Ora, isso demonstra uma incompreensão do valor que se atribuía, no contexto finissecular, ao trabalho da tradução. Muitos grandes escritores, na França ou não, foram também tradutores. Apenas a título de referência (a nomes próximos de Proust e sua obra), Baudelaire traduziu poemas e contos de Edgar Allan Poe, e Mallarmé traduziu Poe, Tennyson e ensaios sobre arte e crítica de arte de James Whistler. Em 1900, foram lançados, na França, os 16 volumes da tradução das Mile Uma Noites (terceira tradução da obra, até então, no país) feita por Joseph-Charles Mardrus - tradutor que Proust conheceu pessoalmente. O acesso a obras estrangeiras, sua tradução e debate, constituem um dos elementos que caracterizam a modernidade da literatura cosmopolita da virada do século - e de seus artistas.

A importância atribuída por Proust às traduções e aos tradutores é patente em diversos momentos de sua obra. Dentre as várias menções, a elas e a eles, existentes em $A$ la Recherche du 
Temps Perdu, podem-se destacar duas, que exemplificam o que se expõe aqui. A primeira, quando a mãe do narrador lhe envia duas versões das Mil e Uma Noites, a de Galland e a de Mardrus (que revelam duas leituras diferentes suplementares, a da mãe e a da avó de Marcel, e cuja comparação serve ao narrador como reflexão sobre a leitura; PROUST, Sodome et Gomorrhe, p. 230). ${ }^{2}$

Outro exemplo se encontra no tomo final, quando Jupien faz alusão à tradução que Marcel fizera de Sésame et les lys e enviara a Charlus (PROUST, Le Temps Retrowvé, p. 139) - nomeando o livro e o autor e incluindo um elemento autobiográfico (entre inúmeros outros que são semeados ao longo do romance), que liga, tantos anos depois, Proust à sua fase de tradutor.

Vistas de forma retrospectiva, as traduções de Ruskin funcionaram, sobretudo, como instrumento de busca da respeitabilidade perdida. Pois a publicação de Les Plaisirs et les jours fora um fracasso e rendeu a Proust a pecha de literato decadente e medíocre. Seu próximo projeto literário, Jean Santevil, coleção de textos incoesos, foi escrito entre 1895 e 1899, permaneceu engavetado (publicação póstuma em 1952) e foi descrito pelo autor como uma "coleção de ruínas" (em carta escrita em dezembro de 1899, PROUST, Corr. II, p. 376). Contre Sainte-Bewve, esboço inacabado escrito depois das duas traduções, também possui caráter fragmentário, mas, juntamente com estas, abriu via à concepção da arquitetura da Recherche (cuja redação foi iniciada em 1909). Pode-se considerar que as traduções desempenharam um papel importante na reorientação do projeto literário de Proust. ${ }^{3}$

A conquista progressiva do prestígio ocorre na medida em que Proust não se limita a verter o texto de uma língua a outra. $O$ trabalho de anotação crítica que o escritor realiza paralelamente à redação da tradução resulta numa tradução peculiar, em que o comentário se torna mais relevante do que o texto original - na França. Embora Proust até tenha tentado se manter fiel à intenção de Ruskin (o que se constata nas inúmeras consultas feitas a amigos e tradutores ao longo de sua correspondência pessoal), ele não realizou o que preconizam certas escolas, segundo as quais o tradutor deve se apagar diante do autor. Proust rivalizou com Ruskin nos dois livros que traduziu; criou seu próprio mosaico de erudição e o sobrepôs ao de Ruskin. Criou, sobretudo, uma tradução híbrida, que mistura ensaio, crítica, autobiografia e tradução, impregnando-se do hibridismo do próprio texto traduzido (que mistura ensaio, crítica, imprecação e autobiografia ao embaralhamento geral do texto). A um só tempo, firmou-se como ensaísta, crítico e teórico e cunhou a prosa poética que vai alavancar o interesse do público leitor e cativá-lo no decorrer do longo período de edição dos tomos da Recherche.

No que se refere ao interesse da tradução em si, é preciso não esquecer a importância

\footnotetext{
${ }^{2}$ Mais ou menos na mesma época da redação desse volume, Proust escreve ao amigo Jean Cocteau, referindo-se também à comparação entre as duas versões das Mil e Uma Noites: "Cher Jean quelle chose étrange que vous me parliez de Mardrus au moment où je le compare à Galland” (PROUST, Correspondance XVIII, 1919, p. 594). Para facilitar a compreensão da inclusão das citações no conjunto das coleções a que pertencem, as referências aos tomos da edição da correspondência pessoal de Proust serão feitas de maneira abreviada e as à Recherche vão identificar o título do volume.

3 “A "fase ruskiniana”, expressão do próprio Proust, seja lá qual for a sua importância no conjunto de sua obra literária, tem início de maneira fragmentária em 1893 por meio da leitura de trechos esparsos da obra do pensador britânico publicados no Bulletin de l'Union pour l'Action morale; se intensifica a partir de 1899, quando do encontro do capítulo "La Lampe de la Mémoire" (de importância capital na ulterior evolução da temática proustiana) e de 1900, por ocasião da morte de Ruskin; e atinge seu ápice no decorrer do esforço laborioso de tradução e comentário de La Bible d'Amiens e Sésame et les Lys (1900 - 1906).
} 
de John Ruskin à época: esteta, moralista, teórico, sociólogo, reformador socialista, crítico de arte, desenhista, colecionador de arte e mecenas, John Ruskin era um dos nomes mais respeitados - e polêmicos - da Inglaterra do fim de século. E, embora a crítica francesa costume desconhecer ou desconsiderar o valor e a importância da obra de Ruskin no cenário mundial, não se deve esquecer que foi depois da leitura de Unto this Last, livro de Ruskin sobre política e economia, que Gandhi idealizou sua política de resistência pacífica (contra, justamente, o imperialismo inglês). Em sua autobiografia, ele dirá, a propósito de seu primeiro contato com o trabalho do autor: "Não consegui dormir aquela noite. Resolvi mudar minha vida segundo os ideais do livro" (ver http://www. wattpad.com.93728-sarvodaya-written-by-mohandas-k-gandhi; essa obra e seu conceito de "força da alma" como substituta da força física levaram-no, também, a se tornar, como Proust, tradutor de Ruskin, para o gujarati).

\section{A polêmica}

As traduções empreendidas por Proust são editadas em meio a um cenário de polêmicas e querelas, característico no meio intelectual e artístico dos grandes centros culturais do fim do século XIX e início do século XX. E Proust se insere nesse quadro, tirando partido da polêmica para marcar sua personalidade literária e sua independência intelectual junto aos seus pares na França.

Em seu ensaio La Venise intérieure. Proust et la poétique de la traduction, o crítico suíço Edward Bizub insere o interesse por Ruskin no contexto da querela entre os nacionalistas e os que preconizam a leitura e a influência das literaturas estrangeiras e cita a interessante advertência de um importante nacionalista à época: "corram e aproveitem, vocês que gostam dos escritores das neves e das brumas, pois pode ser que uma reação do gênio latino esteja próxima" (Jules Lemaître, "De l'influence récente des Littératures du Nord", La Revue des Deux Mondes, 15/12/1894, p. 872, apud BIZUB, 1991, p. 44).

A querela travada no meio literário opõe, muito categoricamente, a (suposta) clareza francesa e as (projetadas) "brumas" nórdicas (ou mais especificamente inglesas). Bizub, que considera essa querela como uma "crise de visão" (ibidem) ressalta que, durante a última década do século XIX, os nacionalistas temiam uma "invasão" das literaturas estrangeiras (idem, p. 43); já seus antagonistas buscam afinidades com elas. O Bulletin de l'Unionpourl'Action Morale de dezembro de 1895 apresenta assim três grandes escritores anglo-saxões, que serão muito admirados por Proust:

Ralph Emerson, Thomas Carlyle, John Ruskin: guardem estes três nomes. Eles têm uma sonoridade estrangeira; mas são nomes amigos. O enérgico espírito anglo-saxão não pertence exclusivamente aos habitantes da grande ilha e do novo continente; no fundo de todos nós, franceses, italianos, alemães, há afinidades com eles; todos carregamos um pouco da Inglaterra dentro de nós. (apud BIZUB, 1991, p. 46).

A noção de uma "Inglaterra interior" vai marcar a estética de Proust e está diretamente ligada à "crise de visão" contemporânea. Ela acirra os ânimos da querela e desencadeia a busca de 
uma expressão em sintonia com as necessidades da criação poética do fim do século, o que não deixa de remeter a uma das grandes questões dessa crise: o fato de a Inglaterra ser o primeiro país industrial e na vanguarda tanto dos problemas quanto da busca de soluções ao novo status quo. Essa crise é uma das facetas da questão da modernidade - que tão fortemente impressiona os escritos de Proust.

Essa "Inglaterra interior" já pode ser identificada de maneira geral tanto no texto de Proust quanto na maneira como ele será lido por seus pares: a escritura de Proust receberá severas críticas, sobretudo por seu caráter impreciso (ou confuso), extenso (para não dizer cansativo), sinuoso (ou decididamente labiríntico) e nitidamente antagônico à concisão clássica preconizada. E essa será a recriminação recorrente contra o texto de Proust: ele não escreve "como um clássico", no sentido da concisão e da clareza defendidas. E muitos críticos dirão que Proust herdou seu estilo tortuoso (de longas frases encaixadas) de Ruskin - crítica que rende, até hoje, querelas entre estudiosos francófonos e anglófonos da obra de Proust e gera debates quanto à sua independência intelectual e à originalidade de sua personalidade literária.

Coadunado com o espírito de sua época, em pleno início da redação da Recherche, Proust vai comentar a importância da literatura estrangeira e, particularmente, a inglesa e a norte-americana, como sendo constituintes do seu "panteão" de obras preferidas:

Je viens de lire une très belle chose qui ressemble malheureusement un tout petit peu (en mille fois mieux) à ce que je fais: La Bien-Aimée de Thomas Hardy. Il n'y manque même pas la légère part de grotesque qui s'attache aux grandes oeuvres (...) C'est mieux que dans tous les genres les plus différents, de George Elliott [sic] à Hardy, de Stevenson à Emerson, il n’y a pas de littérature qui attire sur moi un pouvoir comparable à la littérature anglaise et américaine. L'Allemagne, l'Italie et bien souvent la France me laissent indifférent. Mais deux pages du Moulin sur la Floss me font pleurer. Je sais que Ruskin exécrait ce roman-là, mais je réconcilie tous ces dieux ennemis dans le Panthéon de mon admiration. (Carta ao amigo e diplomata Robert de Billy, [março] 1910, PROUST, Corr. X, p. 54-5).

Os dois primeiros autores citados são, eles próprios, também tradutores. Esse "poder" das literaturas inglesa e norte-americana exercido sobre Proust passa necessariamente pelo viés da tradução, pois ele não domina o idioma inglês. $\mathrm{O}$ elogio aos autores se estende, inevitavelmente, ao trabalho dos tradutores.

Dentre os autores "nórdicos", Ruskin tinha posição de destaque pela sua estatura na própria Inglaterra, pela monumentalidade de sua obra em vias de tradução para diversos idiomas e, a partir de 1900, quando de sua morte, por ter sido lançado no cerne de uma corrida editorial (em vida, Ruskin proibira a tradução de seus livros para o francês; com sua morte, cai o interdito). Pode-se dizer, como Charles Maurras (poeta e jornalista monarquista e "arqui-nacionalista"), que Ruskin se tornou um fenômeno de moda:

Já que John Ruskin está na moda, o senhor Marcel Proust tem toda a razão de traduzir Ruskin. Depois da Bible d'Amiens... [ele] acaba de verter para o francês 
Sésame et les Lys. Com símbolos e imagens, como os pré-rafaelitas, não é, porém, um livro menor. Parece-me que o verdadeiro caráter de Ruskin foi alterado na França pelo excesso de delicadeza e de elegância com a qual nos foi apresentado... Os senhores de la Sizeranne, Jacques Bardoux, Marcel Proust são pessoas amáveis e dóceis. Fizeram Ruskin à sua imagem... [mas Ruskin foi] um dos mais severos censores de seu tempo. (trecho transcrito em nota a uma carta de Proust ao crítico Paul Souday, [1906], PROUST, Corr. VI, p. 141-2)

Por ser, entre outras coisas, reformador socialista, evangelizador e moralista, os escritos de Ruskin sofreram alguma resistência na França e a opção pela tradução de seus títulos também foi criticada. Aqui, Proust não é visto como diletante (enquanto autor de Les Plaisirs), mas como alguém "dócil” que "altera” ou deforma o "ácido censor" que é Ruskin, segundo Maurras, para torná-lo palatável ao leitor francês. Não são apenas os três tradutores e ensaístas (La Sizeranne, Bardoux e Proust) que estão sendo criticados nesse artigo, é toda uma política editorial que vinha incentivando a difusão da obra de Ruskin (entre outros "nórdicos”) na França.

Outro aspecto polêmico das traduções de Proust refere-se à competição pelo título de maior autoridade sobre Ruskin à época. A leitura da correspondência de Proust permite afirmar que essa concorrência ocupou o interesse de Proust durante algum tempo, inclusive como meio de tentar mudar a visão de seus pares sobre seu trabalho. Proust vai rivalizar com o maior especialista em Ruskin até então, Robert de La Sizeranne, citado acima por Maurras, autor de vários artigos e do ensaio Ruskin et la religion de la beauté (1897), que Proust terá a oportunidade de criticar em seus comentários e notas (sobretudo em La Bible d'Amiens) - o que valoriza seu ingresso no âmbito das querelas.

Outra polêmica que se detecta no exame da correspondência de Proust é a questão da qualidade e da própria autoria das traduções. Muitos leitores, sobretudo no lançamento do primeiro livro traduzido, vão reclamar de erros e contrassensos na tradução; vão, também, sugerir (e isso ainda é discutido por especialistas nos dias de hoje) que Proust apenas burilou o trabalho de tradução literal realizado pela mãe, além de depender da contribuição e revisão da amiga inglesa Marie Nordlinger (e das consultas a vários amigos bilíngues e tradutores).

Uma última polêmica que envolve Proust e sua visão de Ruskin deve-se ao famoso, à época, "Processo de Whistler contra Ruskin". Talvez a primeira menção nominal a Ruskin na obra ficcional de Proust seja a curta referência a esse processo em Jean Santemil: "[Jean] va finir par raconter le procès de Ruskin et de Whistler qui m’intéresse beaucoup" (no fragmento "La Première de Frédégonde", PROUST, 1971b, p. 678). Ruskin dissera que o quadro do pintor norte-americano James McNeillWhistler (1834-1903), Nocturne in Black and Gold: The Falling Rocket (1874), era um embuste. Quatro anos depois, Whistler vence Ruskin num processo por difamação. Depois do quê, o pintor escreve, a seu respeito, o livro The Gentle Art of making enemies (que Proust recebe de presente do amigo Robert de Montesquiou, um dos modelos do personagem Charlus, em 1896; apud PAINTER, 1966, p. 323. Por coincidência, Whistler pintará um retrato de Montesquiou - a quem Proust chama de "professeur de beaute" em um artigo em Contre Sainte-Beuve, o que lembra a apelação de "Maître de Beautê", conferida por La Sizeranne a Ruskin). O processo é detalhadamente descrito por La Sizeranne no ensaio La Peinture anglaise (1895) e o caso suscita debates acalorados. 
A mera menção a Whistler - que vai se repetir em seus escritos a partir de então -, e seu antagonismo a Ruskin, anuncia o que é definido, logo a seguir, como a traição a Ruskin.

Apesar das polêmicas, ou graças a elas, Proust pôde refazer sua entrée no meio literário de maneira prestigiosa. Além de críticas, recebeu louvores de pessoas de destaque (Henri Bergson, por exemplo), teve reconhecidos sua erudição e seu talento poético, conseguiu mudar a recepção a seus escritos junto a seus pares. Ainda assim, foi difícil obter um editor para o primeiro volume da Recherche. Como ocorrera com Les Plaisirs et les jours, Un Amour de Swann será financiado pelo próprio autor; o segundo volume, porém, A l'Ombre des Jeunes Filles en Fleurs, recebe o prêmio Goncourt (1919) - o que sanciona o processo de reversão da apreciação de sua obra

\section{A traição}

Inicialmente, Proust usa suas traduções e comentários como maneira de modificar a opinião sobre seu trabalho e de se projetar no meio intelectual e artístico da época. Mas, após a febre editorial desencadeada pela morte de Ruskin, a aceitação dos escritos do esteta passa por um declínio, até atingir uma verdadeira rejeição, vinte anos depois (hoje, na França, das duas tradições feitas por Proust, só se leem e estudam os prefácios e as notas do tradutor).

Por isso mesmo, a trajetória da admiração de Proust por Ruskin tem um percurso revelador. Por exemplo, quando Proust ainda estava começando o primeiro esboço de sua tradução, ele pede que a mãe lhe envie "le livre de la Sizeranne sur Ruskin s'il est dans ma bibliothèque pour voir les montagnes avec les yeux de ce grand homme" (02/10/1899, PROUST, Corr. II, p. 357). Ao saber da morte de Ruskin, afirma à amiga (e cotradutora dos dois títulos de Ruskin): “quand j'ai appris la mort de Ruskin, j'ai voulu exprimer à vous plutôt qu'à tout autre ma tristesse... je sens combien c'est peu que la mort en voyant combient vit avec force ce mort, combien je l'admire, l'écoute, cherche à le comprendre et lui obéir plus qu'à bien d'autres vivants' ([jan/1900] PROUST, Corr. II, p. 384-385).

Já terminadas as traduções, o tomé outro, mas, mesmo assim, Proust continua considerandoo como um grande artista: em carta ao escritor Georges de Lauris, o tradutor comenta que "Ruskin a dit quelque part une chose sublime (...) Cela n'empêche pas les ouvrages de Ruskin d'être souvent stupides, maniaques, crispants, faux, ridicules, mais c'est toujours estimable et toujours grand' ([08/11/1908], PROUST, Corr. VIII, p. 285-6) - contradição que justifica a admiração passada enquanto anuncia a rejeição ulterior ao pensador.

Na mesma época, ao amigo e escritor Robert de Montesquiou, Proust não só relativiza sua admiração por Ruskin, como registra uma mudança na atitude de algumas revistas especializadas, que passam a elogiar o trabalho do pensador britânico (quando, à época do lançamento de suas traduções, tinham dele - e delas - uma visão crítica: "J'ai d'ailleurs aimé Ruskin avec un extrême scepticisme dont j'ai même marqué, toute révérence gardée, l'étendue. Et voici que si j'en crois le ton général de certaines petites Revues, ceux qui m'ont le plus reproché ma faiblesse à son égard, en font maintenant un dieu sans défauts, sans mélange du périssable" ([nov/1908], PROUST, Corr. VIII, p. 273) - exagerando a aceitação de Ruskin à época (a qual está em vias de se deteriorar) e invertendo posições, colocando-se contrário aos admiradores do esteta.

Poucos meses de morrer, em carta a Sydney Schiff, Proust parece ter perdido a paciência 
com as incongruências do texto de Ruskin, ou com o que ele considera como uma discrepância entre o artista e o homem:

Entre ce qu'une personne dit et ce qu'elle extrait par la méditation des profondeurs où l'Esprit gît, couvert de voiles, il y a un monde. Il est vrai qu'il y a des gens supérieurs à leurs livres, mais c'est que leurs livres ne sont pas des Livres. Il me semble que ce vieil imbécile de Ruskin qui disait de temps en temps des choses sensées a assez bien exprimé une partie au moins de cela. Je ne sais plus où mais je vous le chercherai si vous voulez ([18/07/1922], PROUST, Corr. XXII, p. 363-4).

De "grande homem" (1899) a "velho imbecil" (1922), a derrocada é incontestável. Talvez Proust tenha gostado de Ruskin por intermitência... Talvez tenha expressado sua admiração em função da conveniência. É o que se compreende à leitura do próximo trecho.

Os inimigos Ruskin e Whistler haviam sido reunidos ironicamente, e simbolicamente, na última edição da revista Renaissance Latine (1905) com a publicação de "Sur la lecture" (título do prefácio a Sésame et les lys), de Proust, e de "James McNeill Whistler", de Jacques-Emile Blanche. Treze anos mais tarde, Proust escreve o prefácio do livro de Blanche, Propos de Peintre, mas, em carta ao autor, faz-lhe o seguinte apelo:

vous m'aviez parlé d'ajouter le nom de Ruskin dans la dédicace. Peut-être vaudrait-il mieux ne pas le faire. Je crois qu'on n'admire pas Ruskin à sa valeur; mais il représente maintenant pour l'opinion, en partie erronée, des écrivains et des artistes, une école d'esthétisme si fâcheuse, que son nom je le crains embrouillerait les choses et jetterait un jour faux, sur moi, ce qui est sans importance, sur vous, ce qui en a beaucoup... pour dissiper tout malentendu sur la mémoire de Ruskin, je crois que ce serait tout à fait inutile. (20/10/1918; PROUST, Corr. XVII, p. 417-8).

Em 1918, portanto, às vésperas da publicação de A l'Ombre des jeunes filles en fleurs e da obtenção do Goncourt, mais uma vez, Proust terá uma atitude oportunista quanto ao trabalho de Ruskin: antes, usara-o como meio de se projetar em meio às polêmicas da época; agora, prefere deixar esquecida a sua admiração para não entrar em polêmica com os seus pares e não prejudicar sua imagem em plena ascensão. Intermitências menos do coração do que de uma estratégia.

Essa estratégia leva ao quase apagamento dos rastros de Ruskin na versão final da Recherche. Mas, nas obras engavetadas, ele é mencionado algumas vezes. Em Jean Santeuil, em "Une chambre d'hôtel", o narrador afirma que "Ruskindit que nous devons tout décrire, qu'il ne faut pas écarter tel ou tel objet car tout est poétique" (PROUST, 1971b, p. 556); em "Dînerenville”, numa única frase, são encadeados Ruskin, Rembrandt, Turner, Fontainebleau e a Inglaterra (ibidem, p. 572); em "La première de Frédégonde", Proust cita o processo de Whistler contra Ruskin (já mencionado, idem, p. 678); e em "Arrêt dans un village", o narrador medita sobre a permanência de Ruskin na memória dos aldeães que conviveram com ele (idem, p. 880-8).

Ruskin também é nomeado em Contre Sainte-Beuve: em "Fin de Baudelaire", é listado entre 
os múltiplos rostos "do grande poeta único" (PROUST, 1971a, p. 262); e em "Rembrandt", o narrador se depara com Ruskin numa exposição do pintor flamenco (ibidem: 659-664). Em "Conversation avec maman”, a mãe do narrador lê em voz alta a descrição da entrada em Veneza feita por Ruskin ("la comparant tour à tour aux rochers de corail de la mer des Indes et à une opale"; PROUST, 1994, p. 112)"; em "Noms de personnes", o narrador compara sua decepção diante da realidade corpórea de Mme de Guermantes com sua decepção diante da fachada de São Marcos (que Ruskin descreveu recoberta de pérolas, safiras e rubis; ibidem, p. 264) 5 .

Haverá apenas quatro menções nominais a Ruskin na Recherche: quando a mãe do narrador pergunta ao menino recalcitrante: "est-celà le voyageur ravi dont parle Ruskin?” (A l'ombre des jeunes filles en fleurs, p. 117); quando Bloch critica o esteta: "aller à Venise... pour boire des sorbets... tout en faisant semblant de lire les Stones of Venaïce de Lord John Ruskin, sombre raseur et l'un des plus barbifiants bonhommes qui soient" (ibidem, p. 307); quando o narrador revela possuir cadernos onde registra notas "relatives à un travail que je faisais sur Ruskin" (PROUST, Albertine Disparue, p. 225); e no diálogo citado anteriormente em que Jupien fala ao narrador sobre a tradução de "Sésame et les lys de Ruskin que j'avais envoyée à M. de Charlus" (PROUST, Le Temps Retrouvé, p. 139).

Talvez não seja coincidência o fato de que duas das quatro menções nominais a Ruskin na Recherche sejam seguidas, poucas linhas depois, de uma referência a Whistler, sem que haja uma relação lógica ou explícita entre elas: depois do comentário sobre o "voyageur ravi” de Ruskin, lê-se: "le noend de velours, la coque de ruban qui eussent ravi dans un portrait de Chardin ou de Whistler" (PROUST, A l'ombre des jeunes filles en fleurs, p. 118) - insistindo sobre "ravi" - como adjetivo e como verbo. E, depois de mencionar o seu trabalho sobre Ruskin, o narrador comenta, em meio a observações sobre quadros e pintores:

Carpaccio... était le peintre auquel, quand je ne travaillais pas à Saint-Marc, nous rendions le plus volontiers visite, faillit un jour ranimer mon amour pour Albertine. Je voyais pour la première fois Le Patriarche du Grado exorcisant un possédé. Je regardais l'admirable ciel incarnat et violet sur lequel se détachent ces hautes cheminées incrustées, dont la forme évasée et le rouge épanouissement de tulipes fait penser à tant de Venises de Whistler. (Albertine Disparue, p. 226).

Mais uma vez, há repetição de um termo em ambos os trechos; aqui, o substantivo "trabalho" (o mesmo trabalho - texto ou tradução - sobre Ruskin).

Essas repetições criam uma sutil e surpreendente aliança entre Ruskin e Whistler e expressam um desejo de alusão indireta a esses antagonistas que, no ver de Proust, no final das contas, não se opunham, de fato. É o que se constata em carta a Marie Nordlinger, onde Proust ressalta que "Ruskin et Wisthler [sic] se sont bien méprisés parce que leurs systèmes étaient opposés. Mais la vérité est une et ils la percevaient tous deux" ([fev/1904]. PROUST, Corr. IV: 53-5). E, também à mesma destinatária, no ano seguinte, acrescenta, em referência a um de seus amigos:

\footnotetext{
${ }^{4}$ Cynthia Gamble identifica o trecho em Les Pierres de Venise (GAMBLE, 2002, p. 159).

${ }^{5}$ As edições de Fallois e de Clarac são diferentes de várias maneiras, inclusive na seleção dos textos. Os dois últimos trechos citados não constam na versão mais extensa de Clarac.
} 
[il] doit avoir en bon Wisthlérien [sic] [du] mépris pour l'admirateur de Ruskin. Mais en réalité je pense que si leurs théories, ce qui est la partie la moins intime de chacun de nous furent opposées, à une certaine profondeur ils se rencontraient plus souvent qu'ils ne le croyaient (...) Moi ne n'ai pas connu Wisthler [sic], qu'un seul soir, où je lui ai fait dire un peu de bien de Ruskin!... Plus je pense aux théories de Ruskin et de Wisthler [sic] plus je crois qu'elles ne sont pas inconciliables. Wisthler [sic] a eu raison de dire dans Ten o'clock que l'Art est distinct de la Morale. Et pourtant Ruskin émet aussi une vérité, d'un autre plan, quand il dit que tout grand art est moralité ([1905], PROUST, Corr. V, p. 41-3).

Proust, esteta não moralista, concilia os dois artistas à primeira vista antagônicos e os alia, à sua revelia, do início de sua obra (em Jean Santeuil, 1895) ao fim, em uma traição à sua inimizade na vida real. É o que se constata, também, na carta de Proust ao amigo Sydney Schiff, em 1920, a propósito da perplexidade de seus leitores diante dos volumes editados até então:

La férocité des lecteurs me fait penser à des pages de Ruskin que vous connaissez peut-être. Et sans doute vous savez aussi l'anecdote de Wisthler [sic] ayant à déjeuner les gens les plus riches d'Angleterre... Est-ce que vous avez été dreyfusard jadis? Je l'ai été passionnément. Or dans mon livre je suis absolument objectif il se trouve que le Côté de Guermantes a l'air antifreyfusard. Mais Sodome et Gomorrhe II sera entièrement dreyfusard et rectificatif. ([01]/09/1920], PROUST, Corr. XIX, p. 434-6).

Ao associar, em 1920, os dois artistas "incomunicantes" ao argumento da ilusão e reversão da posição política de sua obra pela via da retrospecção, Proust desfaz, desnatura e perturba a compreensão de uma dicotomia "real” a rivalidade entre Ruskin e Whistler que, até então, fazia parte do elenco das polêmicas da época.

Essa ideia embasa outra desfeitura de dualidade que alicerça a própria estrutura escritural da Recherche: a projeção inicial da incomunicabilidade entre os caminhos de Guermantes e de Méséglise e a eventual descoberta de sua conexão, ao final da obra.

E o próprio Ruskin está na origem dessa estrutura. Entre as primeiras leituras da obra do esteta, Proust toma conhecimento de Unto this Last (que reúne conferências, entre as quais, "The Two Paths"; em 1896, no Bulletin de l'Union pour l'Action Morale) e reinterpreta a imagem bíblica dos "dois caminhos" que inaugura a apresentação das conferências. Nessa apresentação, Ruskin adverte seu leitor:

Espero que ao longo [desse] livro o aluno possa vir a perceber a insistência sobre uma verdade maior... [e a] responsabilidade por uma escolha, decisiva e inclusiva, entre dois modos de estudo, que envolvem, em última instância, o desenvolvimento, ou estancamento, de todo poder que ele possua... Ele poderá encontrar muitos guias... mas eles serão todos vãos, a não ser que ele reconheça, antes, a hora e o ponto na vida em que o caminho se divide, um caminho levando ao Monte das Oliveiras, outro, ao vale do Mar de Sal [(Mar Morto)]. Há poucas estradas comunican- 
tes, que eu saiba, de um a outro. Que ele faça uma pausa no ponto em que se apartam OS DOIS CAMINHOS. (grifos e tradução meus) ${ }^{6}$.

Proust lê Unto This Laste usa-o em seus comentários às suas traduções. Esse livro é traduzido para o francês por um abade, em 1902, e versa sobre política e economia sob uma perspectiva evangélica. Não teve, portanto, repercussão na França laica, e isso talvez explique o fato de que não haja menção por parte da crítica, "que eu saiba", a esse trecho como sendo originário da ideia, ou ilusão, da incomunicabilidade dos dois caminhos que dividem e caracterizam a geografia de Combray.

É claro que a imagem bíblica dos dois caminhos é um lugar-comum e se encontra no Evangelho de São Mateus. Em Mateus 6, em "A lâmpada do corpo", lê-se: "a lâmpada do corpo é o olho. Se pois o teu olho está são, o teu corpo inteiro estará na luz. Mas se o teu olho está doente, teu corpo inteiro estará nas trevas. Se pois a luz que há em ti é trevas, que trevas!”. A questão moral da visão, portanto, está profundamente arraigada no entendimento da leitura e da opção leitora, segundo Ruskin (questões tratadas de maneira diversa por Proust, mas com rigor e fervor semelhantes).

Em Mateus 7, em “Os dois caminhos”, há um alerta: "Entrai pela porta estreita. Larga é a porta e espaçoso o caminho que leva à perdição, e muitos os que entram por ela; quão estreita é a porta e apertado o caminho que leva à vida, e poucos são os que o encontram”. A oposição entre as opções certa e errada faz parte da dicotomia moralizante de que se serve Ruskin em suas preleções.

Proust, que é tantas coisas, expressa tantas visões ao longo de sua obra, faz interagirem tantas ideias contrastantes e personagens multifacetados em seus livros, marca sua distinção básica com relação a Ruskin por não ser moralista e aponta para a infinitude dos caminhos e das visões. Proust lê e altera a visão moralista de Ruskin, aponta para seu caráter ilusório e idealista e supera o lugar-comum da dicotomia entre os caminhos, assim como o da leitura dogmática.

A pausa ruskiniana - a "pausa no ponto em que se apartam OS DOIS CAMINHOS"serve de molde à do narrador da Recherche que, no Temps Retrouvé, se ausenta por longo tempo dos círculos mundanos. Só que o procedimento será inverso: ao invés de perceber a bifurcação entre os dois caminhos opostos e "de poucas estradas comunicantes", Marcel discerne, finalmente, não somente a comunicabilidade entre os caminhos, como a sua superposição, pois, diante de seus olhos, na recepção na mansão dos Guermantes, fundem-se os habitantes dos mundos até então vistos como estanques - imagem da geografia idealizada da infância, que se desfaz com a chegada da velhice.

\footnotetext{
6 "I hope throughout [this] volume the student will perceive an insistence upon one main truth... [and a] responsibility for choice, decisive and inclusive, between two modes of study, which involve ultimately the development, or deadening, of every power he possesses... Guides he may find many... but all these will be in vain unless he has first recognized the hour and the point of life when the way divides itself, one way leading to the Olive mountains - one to the vale of the Salt Sea. There are few cross roads, that I know of, from one to the other. Let him pause at the parting of THE TWO PATHS" (RUSKIN, 1859, p. 7-8). Tanto "Unto this Last" quanto "The Two Paths", “os dois caminhos”, títulos de duas conferências, são citações do Evangelho de São Mateus, ao qual Ruskin faz alusões constantes e que Proust explicita ao longo dos comentários aos textos que traduz.
} 
A tradução (feita em 1902) de "path" por "sentier", e não "chemin", talvez explique a inatenção da crítica em geral para essa possível origem matricial da dicotomia ilusória de Combray - além do desconhecimento do texto tout court (por ser eminentemente dogmático e ter tido pouca repercussão na França laica da época). O maniqueísmo moralista de Ruskin, cuja geografia possui "poucas estradas intercomunicantes", cede espaço às passagens inusitadas do texto proustiano, que multiplica as possibilidades de ser e de ver, no tempo e no espaço.

Essa qualidade será claramente expressa em Le Temps Retrouvé. Num dos trechos finais do "bal de têtes", o narrador encontra Mlle de Saint-Loup (filha de Gilberte, neta de Swann) e se pergunta: "n'était-elle pas comme sont dans les forêts les "étoiles" des carrefours où viennent converger des routes venues, pour notre vie aussi, des points les plus différents?". A jovem passa a ser o centro aonde convergem as rotas e os caminhos - sobretudo, os da infância do narrador -, verdadeira "transversal" entre fios que se cruzam e embolam na trama espessa do passado, das lembranças, das possibilidades de comunicação e do texto (PROUST, Le Temps Retrouvé, p. 333-5).

A revelação de que havia um caminho comunicante entre os de Méséglise e de Guermantes fora feita por Gilberte (PROUST, Albertine Disparue, p. 268), numa primeira transversalidade, que prepara para a segunda, o encontro com Mlle de Saint-Loup. A compreensão paulatina da comunicabilidade, da transversalidade, é um entendimento poético, mais que a constatação das transformações sociais ocorridas no tempo vivido (a fusão dos burgueses e dos aristocratas com caminhos aparentemente estanques de Combray) e no espaço percorrido pelo narrador.

Essa expressão da comunicabilidade é, também, e, fundamentalmente, uma "traição" à doutrina de Ruskin, uma tradução ou interpretação muito pessoal de Proust, que marca, desde suas primeiras leituras da obra do esteta, uma diferença radical com relação ao mestre. Marca, de maneira evidente - o que deveria aliviar os críticos franceses que defendem a independência de Proust quanto à teoria estética de Ruskin —, a originalidade proustiana.

Subverter a geografia ruskiniana (e bíblica), então, é uma das principais demonstrações da traição tradutora de Proust. A recorrência da menção a Whistler em sua obra é outra.

A primeira vez que Whistler é nomeado nos ensaios de Proust talvez seja por ocasião do artigo sobre a morte de Ruskin, em que Proust menciona o fato de que "il est inutile de rappeler çe procès de Ruskin avec Whistler, dont le somvenir est présent dans tous les esprits” (PROUST, 1971a, p. 440) - o que reforça a importância do binômio, na visão de Proust, dos antagonistas.

Nos textos ficcionais, além das aparições de Whistler que se seguem às menções a Ruskin (como já demonstrado), em nova expressão do binômio, no entendimento de Proust, há várias referências a Whistler e seus quadros, inclusive seus desenhos de Veneza, ao longo da Recherche:

...c'est beau comme du Whistler ou du Velasquez ; ...parfois sur le ciel et la mer uniformément gris, un peu de rose s'ajoutait avec un raffinement exquis, cepedant qu'un petit papillon ... semblait apposer avec ses ailes, au bas de cette 'harmonie gris et rose' [título de uma obra de Whistler] dans le goût de celles de Whistler, la signature favorite du maitre de Chelsea ; ...nombreux portraits de Manet ou Whistler peints d'après des modèles disparus ; ...c'est le golfe d'opale de Whistler dans ses harmonies bleu argent ; ...comme dit Whistler, les bourgeois rentrent... mais vous ne savez même pas qui est Whistler (respectivamente: PROUST, $A$ 
l'ombre des jeunes filles en fleurs. p. 322, 371, 426, e PROUST, Le Côté de Guermantes, p. 22 e 546; esta última citação se refere a um trecho de "Le ten o'clock de M.Whistler").

Whistler é um dos pintores que compõem o personagem de Elstir (do qual é um anagrama falho) e sua presença nas descrições de Veneza complementa a de Ruskin (mas esse é o tema de outro ensaio). Vale insistir, aqui, sobre a ideia da repetição: Proust repetira o termo "ravi" - como adjetivo e como verbo (em $A$ l'ombre des jeunes filles en fleurs) e sobre o substantivo "trabalho" (texto ou tradução, em Albertine Disparue), associando, de maneira indireta, mas inequívoca, os dois inimigos confessos.

Talvez haja uma simbologia mais consistente nessa associação. Há um terceiro trecho em que Whistler é mencionado (sem, no entanto, que se detecte a proximidade de uma referência a Ruskin) e onde ocorre uma repetição:

Je n'avais plus recours qu'auprès de $\mathrm{M}$. de Charlus, rentré dans une pièce du bas, laquelle accédait au jardin. J'eus tout le loisir (comme il feignait d'être absorbé dans une partie de whistsimulée qui lui permettait de ne pas avoir l'air de voir les gens) d'admirer la volontaire et artiste simplicité de son frac qui, par des riens qu'un couturier seul eût discernés, avait l'air d'une «Harmonie» noir et blanc de Whistler; noir, blanc et rouge plutôt, car M. de Charlus portait... la croix en émail blanc, noir et rouge de Chevalier de l'Ordre religieux de Malte. (PROUST, Sodome et Gomorrhe, p. 52-3; grifos meus)

A repetição é reveladora. Proust insiste sobre o jogo de palavras whist-Whistler (whist sendo um jogo de cartas), dentro de uma cena farsesca, onde Charlus "finge" estar absorto numa partida "simulada" para não parecer estar olhando as pessoas ao seu redor. A presença do pintor aponta para a ideia de embuste - que é a opinião expressa por Ruskin acerca de uma de suas telas célebres. Não deixa de ser uma maneira enviesada de inserir a presença do esteta britânico em mais essa menção ao pintor norte-americano.

Esse trecho, especificamente, é comentado pelo crítico Michael Murphy, que faz uma relação entre Whistler, arte e moda - resvalando para o tema da alta costura e do vestido (uma das imagens proustianas para a estrutura do romance). Seu ensaio é um dos raríssimos textos que mencionam a existência de Whistler na obra de Proust (ver bibliografia).

Porém, o jogo de palavras com o jogo de cartas, mise en abyme de engodos e/ou distrações, enfatiza o gesto disfarçado de Charlus que, afinal, observa sem ser visto (outro engodo) - num espelhismo com o próprio gesto no narrador. As repetições de termos que aliam Ruskin e Whistler podem ser uma maneira simbólica de expressar, no texto ficcional, de forma lúdica, a convicção proustiana de que esses inimigos eram mais complementares do que antagônicos.

Finalmente, podem-se acrescentar outras menções a Whistler além das já citadas anteriormente. Proust menciona Whistler em sua correspondência pessoal. Em uma carta à amiga Marie Nordlinger, diz que conheceu Whistler pessoalmente e que este lhe dissera que Ruskin não entendia nada de pintura ([fev/1904], PROUST, Corr. IV , p. 53-55). Em outra, para a mesma des- 
tinatária, Proust agradece o envio do "delicioso livro" de Whistler, Ten o'clock. A lecture, e comenta que seu amigo Lucien Daudet estudara pintura com o pintor polêmico ([09/02/1905], PROUST, Corr. V, p. 41-3). Em bilhete à mãe, Proust não somente lhe recomenda a exposição de quadros e desenhos de Whistler, como faz um esboço das salas de exposição do museu e indica todas as obras que ela deve ver com atenção ([15/06/1905], PROUST, Corr. V, p. 219-21). Muito mais tarde, à amiga Mme Madrazo, Proust evoca "certains petits Venise de Whistler" ([09/03/1916], PROUST, Corr. XV, p.62) - em alusão a quadros que tanto admira do pintor. As referências não têm desdobramentos significativos.

Entretanto, em outra carta à amiga Marie Nordlinger, Proust comenta:

Vous savez qu'il y a en ce moment dans l'élite artistique en France un terrible recul d'opinion pour Wisthler [sic]. On le considère comme un homme d'un goût exquis qui a pu laisser croire par là qu'il était un grand peintre bien qu'il n'en soit rien. Jacques Blanche dans la Renaissance Latine... a au fond exprimé avec plus de justice et même de ferveur la même opinion. Ce n'est pas du tout la mienne. ([24/06/1905], PROUST, Corr. V, p. 259-62).

Ruskin (morto em 1900) e Whistler (em 1903) conheceram grande notoriedade na França finissecular, animaram os salões e os debates da Belle Époque, mas suas reputações começaram a declinar logo após a "era das traduções" proustiana. Ambos foram sendo esquecidos na França, permanecendo, porém, presentes ao longo da Recherche, associados por repetições de termos e pela própria recorrência das repetições, traídos em sua inimizade e vistos, retrospectivamente, como os caminhos de Combray e da infância, como artistas - vasos? - comunicantes.

\section{REFERÊNCIAS BIBLIOGRÁFICAS:}

GAMBLE, C. Proust as Interpreter of Ruskin. The Seven Lamps of Translation. Birmingham: Summa Publications, 2002.

BIZUB, E. La Venise intérieure. Proust et la poétique de la traduction. Neuchâtel: La Baconnière, 1991.

MURPHY, M. "Proust's Butterfly". In Proust and America. Liverpool: LUP, 2007, p. 195-241.

PAINTER, G. "Le salut par Ruskin". In. Marcel Proust, Vol. I. Paris: Mercure de France, 1966 (1959), p.323-59.

PROUST, M. A La Recherche Du Temps Perdu I - VII. Paris: Gallimard (Folio), 1986-1990.

. Contre Sainte-Beuve (Org. Pierre Clarac e Yves Sandre). Paris: Gallimard, 1971a.

. Contre Sainte-Beuve (Org. Bernard de Fallois). Paris: Gallimard, 1994 (1954).

. Correspondance I-XXI. Paris: Plon, 1976-1990.

- Jean Santeuil (Org. Pierre Clarac e Yves Sandre). Paris: Gallimard, 1971b.

RUSKIN, J. Unto this Last. Londres: Collins, s/d [1859].

TADIÉ, J.-Y. "Introduction”. In. PROUST, M. A la Recheche du Temps Perdu, Vol. I, Ed. Pléiade. Paris: Gallimard, 1987, p.ix-cvii. 